\title{
An Investigative and Explanatory Review on Use of Milk as a Broad-Spectrum Drug Carrier for Improvement of Bioavailability and Patient Compliance
}

\author{
Sukhmeet Singh Kamal, ${ }^{1}$ Daljit Kaur, ${ }^{1}$ Sukhwinder Singh, ${ }^{1}$ Amit Sharma, ${ }^{2}$ Manoj Kumar Katual, ${ }^{2}$ Ashish Kumar Garg, ${ }^{3}$ Rajesh Kumar, ${ }^{1 *}$ \\ "Department of Pharmaceutics, Rayat-Bahra Institute of Pharmacy, Hoshiarpur, Punjab, INDIA. \\ 'B.Pharm., Rayat-Bahra Institute of Pharmacy, Hoshiarpur, INDIA. \\ ${ }^{2}$ M.Pharm, Rayat-Bahra Institute of Pharmacy, Hoshiarpur, INDIA. \\ ${ }^{3}$ M.Pharm, Akal College of Pharmacy \& Tech. Education, Sangrur, Punjab, INDIA.
}

\begin{abstract}
Objective: The main objective of this review is to investigate the potential role of milk in improvement of bioavailability and patient compliance. Method: The study reviews the types of milk based on its composition, mechanism of how milk improves the solubility of poorly soluble drugs, masks the taste of bitter drugs and improves the patient compliance to dosage regimen. It also reviews various research studies done so far that recommend the use of milk in formulations. Along with this, the regulatory aspect of using milk is also considered in the present study. Conclusion: Investigation concludes that medicated milk formulations open a new hope of utilizing milk as multi-functional drug carrier for a variety of drugs.
\end{abstract}

Key words: Milk, Solubility, Bitter, Casein, Fat, Pediatric.

Correspondence :

Rajesh Kumar, M.Pharm., PhD

Department of Pharmaceutics, Rayat-Bahra Institute of Pharmacy, V. Bohan, Hoshiarpur-Chandigarh Road, Hoshiarpur, Punjab-146001, INDIA.

Phone no: +91-9855976499

E-mail: rajksach09@gmail.com

DOI: 10.5530/jyp.2016.2.3

\section{INTRODUCTION}

Despite of tremendous advancement in drug delivery systems, oral route is the most preferred route of administration and hence tablets and capsules are the most preferred dosage forms. However, the drugs having aqueous solubility less than $0.1 \mathrm{mg} / \mathrm{ml}$ at $37^{\circ} \mathrm{C}$ pose a major problem for pharmaceutical scientists. Now since nearly $40 \%$ of the drugs identified by the pharmaceutical industry are found to be poorly water soluble, ${ }^{1}$ it becomes a great challenge to formulate these drugs (e.g. NSAIDs, Antibiotics, Anti-cancer drugs, Antiretroviral drugs etc.) into oral dosage forms owing to their poor aqueous solubility and thus poor bioavailability. In addition, their bitter taste and associated gastric irritation make them less acceptable and thus lead to poor patient compliance especially in paedriatic patients. Therefore, the improvement of solubility and hence the bioavailability is the first and foremost target which can be achieved by modifying the crystallinity and non-polarity of such drugs. ${ }^{2}$ Some modern approaches which can be used are solid dispersions, ${ }^{3}$ micronization, ${ }^{4}$ salt formation, modification of crystal habit, ${ }^{5,6}$ polymeric alterations and inclusion complexes, ${ }^{7}$ spray drying, ${ }^{8}$ solvent evaporation method, high pressure homogenization and lyophilization technique. ${ }^{9}$ The modification of the dissolution media in which drug is dissolved may also improve the dissolution rate. It can be achieved either by adjusting the $\mathrm{pH}$ or by adding co-solvents, ${ }^{10}$ complexing agents, ${ }^{11}$ solubilizing agents ${ }^{12}$ and surfactants. ${ }^{13}$ To some extent, the above mentioned methods do take care of solubility and bioavailability related challenges, however, they don't avoid some inevitable side effects like gastric irritation, abdominal pain, nausea and diarrhoea.

It has been disclosed in many published studies that milk offers a great solution to the above mentioned challenges without any noticeable side effect. Use of milk as a dispersion carrier in pharmaceutical formulations offers following benefits:

1. Solubility of lipophilic drugs both in ionized as well as unionized forms, is higher in milk than their aqueous solubility.
2. Due to its taste masking ability, milk can be a good carrier for bitter drugs especially in pediatric patients.

3. Milk, due to its natural properties, is able to remediate the gastric side effects to a great extent.

4. Milk is naturally occurring oil-in-water emulsion which is inexpensive and is available abundantly.

\section{Classification of Milk}

Based on the content of fat present, milk can be classified into 3 main categories namely full fat milk; semi skilled milk and skimmed milk. Other than fats, milk contains a rich content of protein and carbohydrate also. Composition of above classified categories of milk along with calories of energies it carries is given in Table 1.

\section{Composition Based Mechanism of Milk}

The composition of milk varies due to differences in relative rates of synthesis and secretion of the milk component by the mammary gland. The mammary epithelial cells secrete milk as fat globules whose average size is $3 \mu \mathrm{m}$ in diameter but can vary from 1-18 $\mu \mathrm{m}$. These fat globules are encapsulated by a lipid bilayer membrane which consists of proteins, phospholipids, lipoproteins, cerebrosides, nucleic acids, enzymes, trace elements and bound water. The fat globule in the aqueous environment of the milk serum is stabilized by the FGM (Fat Globule Membrane). The fat contained in the milk belong to the group of esters, which are composed of alcohol and acids. ${ }^{15}$

There are two different types of protein present in milk- casein and whey. Casein consists of $80 \%$ of total protein content and is further classified into five categories as alpha $\mathrm{s}_{\mathrm{s} 1}$, alpha $\mathrm{s}_{\mathrm{s}}$, beta, gamma and kappa caseins. Casein acts as highly effective surface active agent owing to presence of hydrophobic as well as hydrophilic regions in its amino acids. ${ }^{15}$ Whey proteins present in milk such as $\beta$-lactoglobulin, $\alpha$-lactoalbumin, bovine serum albumin and immunoglobulins have better solubility as compared to caseins. ${ }^{16}$ 
Most of casein proteins present in skimmed milk exist in a colloidal particle state as the casein micelle. It has been observed that hydrophobic drug is entrapped by the casein micelles. Due to their surface active properties, there is an improvement in the solubility of the drug substance in gastric media when administered orally. These micelles have a porous structure which helps in the release of entrapped drug molecules from the inclusion complex into the dissolution media. ${ }^{17,18}$ In addition to casein micelle, casein submicelle model was also suggested according to which, there exist small aggregates of whole casein which contain 10-100 casein molecules known as submicelles. Based upon the presence or absence of kappa casein, two different types of submicelles are assumed: with and without kappa casein. These submicelles are composed of a hydrophobic core and have a hydrophilic coating which is partly comprised of kappa-casein, polar moieties that exhibit surface activity. ${ }^{19,20}$

Some studies showing the utility of milk in overcoming solubility problems, gastric irritation and bitter taste of drugs are quoted here.

The solubility of lipophilic drug in powdered form is much higher in milk as compared its aqueous solubility. ${ }^{21}$ Use of skimmed milk is also preferred over polymers in case of poorly soluble or lipophilic drugs because of their own high viscosity. ${ }^{16}$ It also represses gastric irritation and hence no abdominal pain is noticed with the use of milk as a dispersion medium with NSAIDs. ${ }^{22}$ NSAIDs are advised to be administered with milk to reduce the side effects that appear with their use like gastric irritation which is due to COX inhibition.

In another study, a novel nipple shield delivery system (NSDS) for antiretroviral drug administration to infants during breast feeding was prepared. ${ }^{23}$ The API released directly into milk during breastfeeding. This study investigated the feasibility of using the NSDS to deliver the microbicide sodium dodecyl sulfate (SDS), with the goal of preventing mother-to-child transmission (MTCT) of HIV during breastfeeding in low-resource settings, in the absence of safer alternative for the infant but to breastfeed. This proof of concept study demonstrated that efficient drug delivery to breastfeeding infants was achievable using the NSDS.
A number of other in-vitro and in-vivo studies with milk formulations of different active substance have shown their superiority in terms of dissolution and solubility. ${ }^{24}$

In 1987, Dial et al. studied antiulcer activity of pasteurized bovine milk and its lipid extract using $0.6 \mathrm{~N} \mathrm{HCl}$, absolute ethanol and acidified bile acid as ulcerogenic agents in rats. Their ulcerogenic effects were significantly pacified with prior administration of milk. The lipid content of milk such as prostaglandins and phospholipids were observed to have potent antiulcer activity. This activity of milk is due to its ability to maintain the hydrophobicity of the gastric lumen by maintaining the major phospholipids in their cationic form which promote their adsorption to the negatively charged mucosal surface. Protein content present in milk was observed to be responsible for stimulant action on acidic secretions and hence for the maintenance of an acidic environment within the gastric lumen. The phospholipid content of skim milk is about $40 \%$ that of whole milk and buttermilk is about $300 \%$ that of whole milk. This phospholipid content in milk products was directly related to the protective efficacy. From this study, it was concluded that when $0.6 \mathrm{~N} \mathrm{HCl}$ was used as a damaging agent in pylorus ligated rats, the protective active activity of milk was found to be due to its phospholipid content, rather than protein content. ${ }^{25}$

In 1995, Dial et al. studied the ability of dairy foods such as whole milk$3.5 \%$ fat, skimmed milk- $0 \%$ fat and cream- 35\% fat, to prevent bleeding and stress induced gastric lesions in rats. From this study Dial concluded that cream owing to its high fat content provided the greatest protection whereas the non-fat milk provided lowest protection. ${ }^{26}$

\section{Milk Based Formulations}

The main aim of developing milk as a dispersing carrier is in-vivo solubilization of sparingly soluble active ingredients and thus to enhance the bioavailability of ionized and unionized lipophilic drugs. ${ }^{1}$ So, the manufacturing of these formulations can be achieved by using three approaches: ${ }^{16}$

Table 1: Classification and composition of Milk based on fat content (per 100g) ${ }^{14}$

\begin{tabular}{|c|c|c|c|c|c|}
\hline Sr. No. & Milk & Fats (g) & Proteins $(\mathrm{g})$ & Carbohydrates (g) & Energy (kcal) \\
\hline 1 & Full fat milk & $\begin{array}{c}3.9 \\
\text { Saturated- } 2.5 \\
\text { Monosaturated- } 1.0 \\
\text { Polysaturated- } 0.1 \\
\text { Trans fatty acids- } 0.1\end{array}$ & 3.3 & 4.7 & 66 \\
\hline 2 & $\begin{array}{l}\text { Semi skimmed } \\
\text { milk }\end{array}$ & $\begin{array}{c}1.7 \\
\text { Saturated- } 1.1 \\
\text { Monosaturated- } 0.4 \\
\text { Polysaturated- trace } \\
\text { Trans fatty acids- } 0.1\end{array}$ & 3.5 & 4.7 & 46 \\
\hline 3 & Skimmed milk & $\begin{array}{c}0-0.3 \\
\text { Saturated- } 0.1 \\
\text { Manoasaturated- } 0.1 \\
\text { Polysaturated- trace } \\
\text { Trans fatty acids- trace }\end{array}$ & 3.5 & 4.8 & 34 \\
\hline
\end{tabular}

Table 2: Manufacturing approaches for different drugs ${ }^{2}$

\begin{tabular}{ccc}
\hline Sr. No. & Approach & Example \\
\hline 1 & I & Non-steroidal anti-inflammatory drugs (NSAIDs) \\
2 & II & Cyclosporine, Danazol \\
3 & III & Effervescent Aspirin tablets \\
\hline
\end{tabular}


Table 3: Various formulations containing skimmed milk as carrier

\begin{tabular}{|c|c|c|c|}
\hline Sr. No. & Drug substance & Techniques & Results \\
\hline 1 & Atorvastatin $^{16}$ & Solid dispersion by lyophilization & $\begin{array}{l}\text { Solubility was enhanced by } 33 \text {-fold as compared to pure drug with increased hypolipidemic } \\
\text { effect }\end{array}$ \\
\hline 2 & Ketoprofen ${ }^{29}$ & Inclusion complex by freeze-drying & $\begin{array}{c}\text { Four times increase in solubility, improved dissolution, decreased gastrointestinal } \\
\text { disturbances }\end{array}$ \\
\hline 3 & Meloxicam $^{30}$ & $\begin{array}{l}\text { Solid dispersions by Rota vacuum } \\
\text { evaporation technique }\end{array}$ & $\begin{array}{l}\text { Solubility of pure drug was increased by } 3 \text { times, reduced gastrointestinal irritation with } \\
\text { improved pharmacological activity }\end{array}$ \\
\hline 4 & Prednisolone $e^{31}$ & Inclusion complex by lyophilization & Improved solubility, in-vitro dissolution and hence bioavailability \\
\hline 5 & Valsartan $^{32}$ & Solid dispersions & $\begin{array}{c}\text { Decreased crystallinity of the drug which increased its surface area thereby improved the } \\
\text { dissolution rate }\end{array}$ \\
\hline 6 & Indomethacin ${ }^{33}$ & Using povidone of various grades & Dissolution was higher with low viscosity grade of povidone as compared to higher grade \\
\hline 7 & Cefpodoxime $^{34}$ & Solid dispersions & $\begin{array}{l}\text { Enhanced solubility and dissolution, increased retention in upper GIT and protected the } \\
\text { drug from enzymatic attack which resulted in improved bioavailability, reduced dose and less } \\
\text { side effects }\end{array}$ \\
\hline 8 & Lovastatin $^{35}$ & Solid dispersion by using Soluplus & $\begin{array}{l}\text { Soluplus enhanced the surface area of drug by making it amorphous and hence resulted in } \\
\text { increased rate of dissolution }\end{array}$ \\
\hline 9 & Ibuprofen $^{36}$ & Inclusion complex by lyophilization & $\begin{array}{l}\text { Solubility was found to be } 20 \text { times higher than plain drug, Witepsol W35 suppository base } \\
\text { (rectal suppository) depicted the highest drug release }\end{array}$ \\
\hline 10 & $\begin{array}{l}\text { Ketoprofen and } \\
\text { Ibuprofen }\end{array}$ & Lyophilization & $\begin{array}{l}\text { Lyophilized milk was found to increase the solubility by dual effects i.e., mixed micelle and } \\
\text { incubation of drug }\end{array}$ \\
\hline 11 & Ibuprofen $^{38}$ & $\begin{array}{l}\text { Lyophilized milk by using Chitosan } \\
\text { as drug carrier }\end{array}$ & Prepared Ibuprofen beads had extended drug release and decreased GIT irritation \\
\hline 12 & Carvedilol $^{39}$ & $\begin{array}{c}\text { Solid dispersion using rota } \\
\text { evaporation and lyophilization } \\
\text { methods }\end{array}$ & Improved solubility, dissolution rate and stability of poorly soluble drug \\
\hline
\end{tabular}

1. Ionized acidic lipophilic drug solution is prepared in an alkaline buffer.

2. Unionized lipophilic drug solution is prepared in water- ethanol mixtures.

3. Solution of moderately water soluble drug from an effervescent tablet is prepared by using small volume of water $(20 \mathrm{ml})$.

Then this dissolved drug is incorporated into a specific volume of milk which may be administered instantly or undergoes further processing before administration. This method of manufacturing is appropriate for several chemically as well as pharmacologically different drugs which include OTC (over the counter) and widely prescribed drugs like nonsteroidal anti-inflammatory drugs viz. Meloxicam, Tenoxicam, Nimesulide, Mefanamic acid, Tolfenamic acid, Ketoprufen and Ibuprofen. Other such drugs include antiretroviral agents, several antibiotics and anticancer agents. ${ }^{27,28}$

Table 3 briefly summarizes the milk based formulations, the techniques used therein to formulate them and the results obtained with the formulations.

\section{Regulatory Aspects}

Milk based formulations are considered as a novel, simple and physiologically friendly approach for the delivery of lipophilic drugs. The strong buffering capacity of milk makes the use of alkaline buffers of non-steroidal anti-inflammatory drugs possible in these formulations to accommodate the therapeutic doses of NSAIDs. For this reason, this approach can be considered universal for ionized as well as unionized lipophilic drugs. ${ }^{16}$

Milk has not been officially registered as an excipient from a regulatory aspect; but casein which is considered as a major protein present in the milk is included in the list of Generally Recognized as Safe (GRAS) substance. ${ }^{1}$ GRAS certifications and notices exhibit FDA's confidence in the safety of the milk-derived ingredients.
GRAS submitted information in the following areas: ${ }^{40}$

- The identity and specifications for the concentrated milk proteins

- The manufacturing process for the concentrated milk proteins

- The intended use and an estimation of consumption of the concentrated milk

\section{CONCLUSION}

Milk is highly nutritious drink with rich content of nutritive elements and a wide range of biologically active peptides. Milk made formulations provide a simple, novel and patient friendly approach for the delivery of ionized as well unionized hydrophobic drugs. Incorporation of milk in the formulation results in solubilization of drugs with enhanced pharmacokinetic properties. Taste masking and gastro-protective properties also prove it a promising carrier for drugs. Further in-vitro studies are yet to be to be carried out to elucidate the colloidal stability of resulting emulsion, particle size and distribution of milk component. Also the use of lactose free milk for these formulations is still to be explored for patience with lactose intolerance. Finally these medicated milk formulations open a new hope of using milk as a natural dispersing agent and a broad spectrum drug carrier for a variety of drugs.

\section{ACKNOWLEDGEMENT}

Authors are thankful to Dr Chander Mohan, Director-Principal, RayatBahra Institute of Pharmacy for his continuous motivation. Authors also wish to appreciate the optimistic approach of Mr. Mandeep Singh and Mr Sukhjit Singh for availing us the required literature.

\section{CONFLICT OF INTEREST}

The authors have none to declare.

Prior publication: NIL Source of Support: NIL Permissions: NIL 


\section{ABBREVIATIONS USED}

NSAIDs: Non steroidal anti-inflammatory drugs; GRAS: Generally recognised as safe; FDA: Food and drug administration; FGM: Fat globule membrane; COX: Cyclooxygenase; NSDS: Nipple shield delivery system; SDS: Sodium dodecyl sulfate; MTCT: Mother to child transmission; HIV: Human Immundeficiency virus; API: Active pharmaceutical ingredients; $\mathbf{H C l}$ : Hydrochloric acid; OTC: Over the counter.

\section{ABOUT AUTHORS}

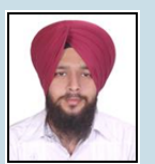

Sukhmeet Singh Kamal: Is pursuing M.Pharm. in Pharmaceutics at Rayat-Bahra Institute of Pharmacy, Hoshiarpur, India. Presently he is working on research project which focuses on improvement of solubility of poorly water soluble drug using milk as a natural polymer. He has published 2 articles in peer reviewed journals and presented posters at various conferences.

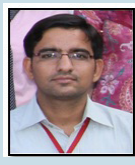

Rajesh Kumar: Is an Asst. Professor in Pharmaceutics at Rayat-Bahra Institute of Pharmacy, Hoshiarpur, Punjab, India. He is teaching B.Pharmacy as well as Post-graduate (Pharmaceutics) students at institute and guiding M. Pharm. Research Projects as well. He has got 6 years of experience in the field and has published more than 15 research \& review articles in various national and international journals including 2 book chapters. His main interest areas in Pharmaceutics are Formulation Development especially Novel Drug Delivery System, Brain Targeting and Improvement of Solubility of Poorly Water Soluble Drugs.

\section{REFERENCES}

1. Waterbeemed H.vd. The fundamental variables of the biopharmaceutics classification system (BCS): a commentary. Eur J Pharm Sci. 1998;7(1):1-3.

2. Charkoftaki G, Kytariolos J, Macheras P. Novel milk-based oral formulations: Proof of concept. Int J Pharm. 2010;390(2):150-9.

3. Argade PS, Magar DD, Saudagar RB. Solid dispersion: solubility enhancement technique for poorly water soluble drugs. J Adv Pharm Edu Res. 2013;3(4):427-39.

4. Rasenack N, Muller B.W. Dissolution rate enhancement by in situ micronization of poorly water soluble drugs. Pharm Res. 2002;19(12):1894-900.

5. Rasenack N, Hartenhauer H, Muller BW. Microcrystals for dissolution rate enhancement of poorly water soluble drugs. Int J Pharm. 2003;254(2):137-45.

6. Rasenack N, Steckel H, Muller BW. Micronization of anti-inflammatory drugs for pulmonary delivery by a controlled crystallization process. J Pharm Sci. 2003;92(1):35-44

7. Pandit V, Gorantla R, Devi K, Pai RS, Sarasija S. Preparation and Characterization of Pioglitazone Cyclodextrin Inclusion Complexes. J Young Pharmacists. 2011;3(4):267-74

8. Wu K, Li J, Wang W, Winstead DA. Formation and characterization of solid dispersions of piroxicam and polyvinypyrrolidone using spray drying and precipitation with compressed anti-solvent. J Pharm Sci. 2009;98(7):2231-422.

9. Hu J, Johnston KP, Williams RO. Spray freezing into liquid (SFL) particle engineering technology to enhance dissolution of poorly water soluble drugs: organic solvent versus organic/aqueous co-solvent systems. Eur J Pharm Sci. 2003;20(3):295-03

10. Yeh MK, Chang LC, Chiou AH. Improving tenoxicam solubility and bioavailability by cosolvent system. AAPS Pharm Sci Tech. 2009;10(1):166-71.

11. Larrucea E, Arellano A, Santoyo S, Ygartua P. Study of the complexation behavior of tenoxicam with cyclodextrins in solution: improved solubility and percutaneous permeability. Drug Dev Ind Pharm. 2002;28(3):245-52.

12. Mutalik S, Anju P, Manoj K, Usha AN. Enhancement of dissolution rate and bioavailability of aceclofenac: a chitosan based solvent change approach. Int $J$ Pharm. 2008;350(1-2):279-90.

13. Larsen A, Holm R, Pedersen ML, Mullertz A. Lipid based formulations for danazol containing a digestible surfactant, Labrafil M2125CS: In-vivo bioavailability and dynamic in-vitro lipolysis. Pharm Res. 2008;25(12):2769-77.

14. The Dairy Council, London. The Nutritional Composition of Dairy products. Available from: http://www.milk.co.uk/resources/resource.aspx?intResourcelD=55.

15. Characteristics of milk. Unit 3, FS/ANS 324. Available from: http://www4.ncsu edu/ adpierce/u03_charateristics_milk.pdf

16. Chaudary A, Rana AC, Aggarwal G, Kumar V, Zakir F. Development and characterization of an atorvastatin solid dispersion formulation using skimmed milk for improved oral bioavailability. Acta Pharmaceutica Sinica B. 2012;2(4):421-8.

17. Atherton HV, Newlander JA. Chemistry and Testing of Dairy Products. $4^{\text {th }}$ ed. Westport: AVI Publications; 1977

18. Walstra P, Geurts TJ, Noomen A, Jellema A, Van Boekel MAJS. In: Walstra P, Geurts TJ, Noomen A, Jellema A, Van Boekel MAJS, editors. Dairy Technology -Principles of milk properties and processes. New York: Marcel Dekker; 1999. P. 485-515.

19. Walstra P. On the Stability of Casein Micelles. J Dairy Sci. 1990;73(8):1965-79.

20. Herb CA and Prud'homme RK. Structure and Flow in Surfactant Solutions. ACS Symposium Series; Washington DC, USA, pp. 380-393;1994.
21. Macheras PE, Reppas C. Studies on drug-milk freeze-dried formulations I: Bioavailability of sulfamethizole and dicumarol formulations. J Pharm Sci. $1986 ; 75(7): 692-6$.

22. Bennet SM, Zhou L, Hayes JE. Using milk fat to reduce the irritation and bitter taste of ibuprofen. Chemosens Percept. 2012;5(3-4):231-6.

23. Gerrada SF, Baniecki ML, Sokal DC, Morris MK, Hartmann SU, Krebs FC. A nipple shield delivery system for oral drug delivery to breastfeeding infants: microbicide delivery to inactivate HIV. Int J Pharm. 2012;434(1-2):224-34.

24. Topaloglou Y, Yener G, Breitkreuz J. Preparation of Sulindac with skimmed milk via freeze drying. Pharmazie. 1998;53(5):327-9

25. Dial EJ, Lichtenberger LM. Milk protection against experimental ulcerogenesis in rats. Digestive Dis Sci. 1987;32(10):1145-50

26. Dial EJ, Romero JJ, Lichtenberger LM. Gasroprotection by diary foods against stress induced ulcerogenesisi in rats. Digestive Dis Sci. 1995;40(11):2295-99.

27. Macheras PE, Koupparis MA, Antimisiaris SG. Drug binding and solubility in milk. Pharm Res.1990;7(5):537-41

28. Macheras PE, Ismailos G, Reppas C. Bioavailability study of a freeze-dried sodium phenytoin-milk formulation. Biopharm Drug Dis. 1991;12(9):687-95

29. Topaloglu Y, Yener G, Gonullu U. Inclusion of Ketoprofen with skimmed milk by freeze-drying. II Farmaco. 1999;54(10):648-52.

30. Kumar SGV, Mishra DN. Preparation and evaluation of solid dispersion of meloxicam with skimmed milk. Yakugaku Zasshi. 2006;126(2):93-7.

31. Sahin NO, Arslan A. Inclusion complex of Prednisolone with skimmed milk part-1: Physicochemical characterization. Yakugaku Zasshi. 2007;127(8):1255-61.

32. Kumar KV, Kumar NA, Verma PRP, Rani C. Preparation and in-vitro characterization of valsartan solid dispersions using skimmed milk powder as carrier. Int J Pharm Tech Res. 2009;1(3):431-7.

33. Patel KM, Biswal B, Karna N, Patel J. Preparation and evaluation of sustain release indomethacine tablets using skimmed milk and povidone. Int J Curr Pharm Res. 2011;3(1):60-2.

34. Sharma N, Jain N, Sudhakar CK, Jain S. Formulation and evaluation of gastro retentive floating tablets containing cefpodoxime proxetil solid despersions. In J Curr Pharm Res. 2012;4(4):82-7.

35. Rajeshwari RK, Abbulu K, Sukdhakar M, Vishwanadham M, Tejaswini MS. Studies on dissolution enhancement of lovastatin using soluplus by solid dispersion technique. Int J Pharmacy Pharm Sci. 2012;4(3):124-8.

36. Nafadi MN, Bukhary HM, Abdelhady MI. Enhancement of solubility and release of ibuprofen from Witepsol W35 suppository base by inclusion with lyophilized skimmed milk. Int J Pharmacy Pharm Sci. 2013;5(1):376-82.

37. Nafady NM. Enhancement of Ketoprofen and Ibuprofen solubility and dissolution by lyophilized milk. Int J Pharm Sci Rev Res. 20014;24(2):332-7.

38. Nafady NM. Pharmaceutical study on extended release lyophilized milk treated ibuprofen beads. World J Pharm Res. 2005;4(1):658-71.

39. Madhok S, Madhok A. Enhancement of solubility and dissolution of carvedilo by solid dispersion technique using rota-evaporation and lyophilization methods. Int J Drug Res Tech. 2015;5(2):81-102.

40. GRAS Notification for Concentrated Milk Proteins: Milk Protein Concentrate (MPC) and Milk Protein Isolate (MPI): GRAS Notice 000444 - Food and Drug Administration. http://www.fda.gov/ucm/groups/fdagov-public/@fdagov-foodsgen/documents/document/ ucm337460.pdf 